\title{
A comparative study of postpartum intrauterine contraceptive device acceptance between vaginal delivery and caesarean delivery of women in a 2nd tire Government hospital in West Bengal, India
}

\author{
Chandralekha Biswas*, Banya Biswas
}

Department of Health and Family Welfare, West Bengal, India

Received: 12 January 2022

Accepted: 09 February 2022

\section{*Correspondence:}

Dr. Chandralekha Biswas,

E-mail: drclbiswas@gmail.com

Copyright: (c) the author(s), publisher and licensee Medip Academy. This is an open-access article distributed under the terms of the Creative Commons Attribution Non-Commercial License, which permits unrestricted non-commercial use, distribution, and reproduction in any medium, provided the original work is properly cited.

\begin{abstract}
Background: About third fourth of the world's population lines in the developing countries. Indian population contributes $17.7 \%$ of world population. Family planning is key factor for declining the population. It is related to every phase of maternity cycle i.e., antenatal, intranatal, postnatal or postpartum. IUCD is one the most effective reversible contraceptive method in family planning program.

Methods: It was comparative study conducted over a period of two years at Gynae \& Obstetrics department in a second-tier hospital in WB in India. Total 984 women had PPIUCD insertion immediately after delivery of placenta in vaginal (group A) and caesarean section (group B) after applying inclusion and exclusion criteria. All women are counseled who delivered at this hospital over the mentioned period, were included in this study. Medical eligibility criteria were used for selection.

Results: Around 50\% of total delivery in both groups were accepted PPIUCD. There are 68\% approximately women accepted PPIUCD who delivered virginally. In primiparous women acceptance of PPIUCD was 45.5\%. Acceptance of postpartum intrauterine contraceptive device was significantly higher in multipara (40.8\%) who delivered vaginally.

Conclusions: Acceptance of PPIUCD was significantly higher in women who delivered vaginally than cesarean section in both primiparous and multiparous women. Most common cause behind this acceptance was family planning counselling and awareness program.
\end{abstract}

Keywords: PPIUCD, Vaginal delivery, caesarean section, Acceptance, Awareness

\section{INTRODUCTION}

India became the first country in the world to launch the Family Planning Programme in 1952. However, the concept of Family planning as a strategy for population control received attention mainly after 1971 population census. This led to an increase in proportion of couples effectively protected from 10.4 percent during 1971-72 to 46.5 percent during $1995-96$ but remained stagnant during 1995-96 through 2003-04 and decreased to 40.4 during $2010-11$. Family planning services is important not only for population stabilization, but it also have undergone a paradigm shift and emerged as one of the interventions to reduce maternal and infant mortalities and morbidities. ${ }^{1}$ In India, over the last 50 years, contraceptive usage has increased four times on an average. Overall contraceptive usage was about $13 \%$ in the 1970 s to $40.6 \%$ in 1992-93 National Family Health Survey (NFHS1 pre ICPD) to $56.3 \%$ in 2005-06 (NFHS3). For rural India this increase has been from $37 \%$ to $53 \% .^{2,3}$ In many states the achieved rates of contraceptive usage are around $70 \%$, which are quite decent. Contraceptive use is highest in West Bengal (71.8\%) followed by Chandigarh $(70.9 \%)$ and lowest in Meghalaya (18.7\%). ${ }^{4}$ Female sterilization continues to account for the most commonly used method accounting 
for two-thirds of contraceptive use $(34.3 \%)$ and male sterilization is still the least used method (1.5\%). Family planning is important not only for population stabilization, but it also improve maternal and new-born survival and health. India's population has crossed 139 crores in the year 2021. It is estimated to reach most populous country in the world..$^{5}$ Government of India has launched not only several family planning programmes which promotes birth spacing but also promotes institutional deliveries all over the country where postpartum family planning services is available. ${ }^{6}$ In India, 65 percent of women in the first year postpartum have an unmet need for family planning. Short interconceptional period in a woman puts her at increased risk of morbidity and mortality. The significance of healthy spacing of pregnancy is emphasized by the fact that nearly $61 \%$ of births in India occur at interval that is shorter than the recommended birth to birth interval of approximately 36 months. ${ }^{7}$ Studies show that pregnancies taking place within 2 yrs of previous birth have higher risk of adverse outcome like abortion, premature labour, postpartum haemorrhage, low birth weight babies, fetal loss and maternal death. So, spacing is important both for maternal and new born survival and health. It reduces maternal and child mortality and morbidity. India's maternal mortality is $113 / 100000$ live births for the period 2016-2018 (according to National sample registration system) i.e. many women to die from pregnancy and child birth complications every year. To improve rural health care and delivery system Govt. of India launched various scheme named "Janani Suraksha Yojana" (JSY), "Janani Shishu Suraksha Yojana" (JSSY) etc. Later was launched by the Government of India on June 1, 2011. It entitles all pregnant women are delivering in public health institutions to absolutely free and no expense delivery, including caesarean section to provide drugs and diagnostics, transportation and neonatal health care up to 30 days postpartum. ${ }^{8}$ Postpartum period is one of the critical times when women need an integrated package of health services including contraceptive advices. At this time women are highly motivated and receptive to accept family planning (FP) methods. ${ }^{7}$

Various postpartum family planning methods include condoms (barrier method), intrauterine contraceptive device, LAM, progesterone only pill or injectable, female and male sterilization. Provision of intrauterine device in immediate postpartum period offers an effective and safe method for spacing and limiting births. IUCD users have higher satisfaction rate (99\% versus $91 \%$ for pill users) and higher continuation rates than users of many other methods. Post-partum intrauterine contraceptive device (PPIUCD), a long acting reversible contraceptive (LARC) contraception in women of reproductive age worldwide. $^{8-12}$ IUCD may be inserted in post-partum period, post abortal or in interval period. PPIUCD insertion can be done following delivery of placenta, during cesarean section, within 48 hours of childbirth. The type of insertion can be categorized as: post placental: insertion within 10 minutes after expulsion of the placenta following a vaginal delivery on the same delivery. Intracaesarean: insertion that takes place during a cesarean delivery, after removal of the placenta and before closure of the uterine incision. Early postpartum: insertion within 48 hours of delivery. Delayed partum (Interval): Insertion at or after 6 weeks of delivery. The IUCD is not inserted from 48 hours to 6 weeks following delivery because there is an increased risk of infection and expulsion. Immediate PPIUCD insertion has many advantages except little higher rate of expulsion. IUCDs provide a high level of efficacy with no systemic metabolic effects. Regular continuous motivation and frequent follow up are not required to ensure efficacy once the device is inserted. So, this method for contraception thereby is good choice for illiterate population also. There are many advantages to Insert of an IUCD immediately after delivery. Mother are strongly motivated for contraception in the postpartum period as she immediately pass through a stress full journey, IUCD assure her that not get pregnant immediately. Minimum side effects of IUCD like pain in abdomen and irregular bleeding which are masked with the after pains and lochia respectively. There are less chances of heavy bleeding as most women have amenorrhea due to lactation. Chance of uterine perforation is less because of thick wall of uterus just after delivery as compare to interval period. The method is convenient for both women and also for their health care providers as it is associated with less discomfort and fewer side effects than interval insertion. ${ }^{13}$ It saves time as it is performed on the same delivery table for post-partum and intra-caesarean insertions and needs minimal additional instruments and supplies. Increased institutional deliveries in India are the opportunity to provide women easy access to immediate PPIUCD. PPIUIUD is a good contraceptive method for lactating women because it has no effect on the quantity or composition of breast milk. ${ }^{14}$ Postpartum IUCD is coitus independent. Expulsion rates may be as high as $10 \%$ but the retention rate is still $90 \%$, thus despite higher expulsion rate for immediate PPIUCDs the public health benefit of the service is higher. The skilled clinician and the right technique of insertion are associated with less expulsion rates. Failure rate of this contraceptive is very little i.e. chances of pregnancy rate of 0.6 to $0.8 / 100$ women year of first year of uses. IUCD provides effective contraception maximum for 10 years (Copper 380A).

\section{Objectives}

The objective of our study was to assess the percentage of acceptance of PPIUCD between vaginal delivery and caesarean delivery of women who attended obstetric ward for delivery in a 2nd tire Government hospital.

\section{METHODS}

This is a prospective hospital-based study conducted from April 2017 to March 2019 in the department of Obstetrics and gynaecology in a state general hospital (2nd tire) in 
West Bengal, India. The objective of this study is comparative evaluation of PPIUCD acceptance among the two modes of delivery groups (after vaginal delivery and intra caesarean delivery group). Total 1969 delivery was conducted over a period of two years. All mother were informed about advantages and importance of family planning including advantages and limitations, complication of PPIUCD. Out of 1969 mother 1221 willing for PPIUCD insertion before delivery. Client Assessment for provision of immediate PPIUCD services was done in two phases after applying inclusion and exclusion criteria. The first assessment was a general review of the pregnant woman's medical history and eligibility for the IUD method as per the WHO Medical Eligibility Criteria. Second assessment was done immediately prior to insertion by the person who will insert the IUCD. All candidates signed an informed written consent. Inclusion and exclusion criteria were applied and were subjected to detailed history, clinical examination and relevant investigations. Inclusion criteria were women in post placental period (within 10 minutes of placental expulsion) in vaginal and caesarean delivery, those willing for PPIUCD insertion and participation in the study. Exclusion criteria were; fever during labour and delivery (Temp $38^{\circ} \mathrm{C}$ ), $\mathrm{Hb}-8 \mathrm{gm} / \mathrm{dl}$, having active STD and other genital tract infection or high risk for STD, H/O ruptured membranes for $18 \mathrm{hrs}$ prior to delivery, uterine abnormalities eg. Bicornuate septate uterus, uterine myomas, manual removal of the placenta, unresolved postpartum hemorrhage $(\mathrm{PPH})$ requiring use of additional oxytocic agents in addition to active management of third stage of labour, liver or renal dysfunction, intrauterine fetal death. Finally 984 mother received PPIUCD after fulfilled all criteria. According to mode of insertion total mother was divided into two groups. Group A was where PPIUCD is inserted after placental expulsion in vaginal delivery. Group B was where PPIUCD is placed after placental removal and before uterine wall closure in caesarean section.

Method of insertion: For post placental vaginal insertion i.e. group A, required a long placental forceps. The instrument was inserted up to the fundus of the uterus, and the IUCD was released. Fundal placement of IUCD is the most important step to reduce expulsion of IUCD. Negotiation of the angle between upper and lower uterine segment is a challenge during insertion. Keeping the hand on the uterine fundus and making the uterine axis straight helps in negotiating the angel. For intracaesarean insertion i.e. Group B, the IUCD was introduced through the uterine incision during caesarean section and placed at the uterine fundus. This was done manually regular ring forceps, since it was not necessary to use a long instrument to reach the fundus. After the placenta was removed, we inserted IUCD and then closed the uterine incision. We never attempted to pass the strings of the IUCD through the cervical os before closure of the uterus as this will displace the IUCD and leave it lower down a the uterine cavity. Both groups were advised to follow up at 6week and 3months after discharge (may contacted through phone) and also advised to come back any time if any complaints like excessive bleeding, unbearable lower abdominal pain with or without chill- rigor and fever, foul smelling vaginal discharge etc. Percentage was used for statistical analysis. All data obtained from the PPIUCD register, delivery register and used ratio, proportion and percentage.

\section{RESULTS}

In current study total number of deliveries were 1969 from April 2017 to March 2019 in this institute, out of that $73.08 \%$ was vaginal birth and $26.92 \%$ was caesarean birth respectively. Total 984 mother accepted PPIUCD though 1221 mother were willing for this device. Table 1 shows, $73.08 \%$ was vaginal delivery in this institution in mentioned 2 years. Maximum percentage of vaginal delivery and minimum caesarean section occurred in multiparous women (Table 1-2).

Table 1: Total number of delivery (vaginal delivery and caeserean delivery).

\begin{tabular}{|c|c|c|}
\hline $\begin{array}{l}\text { Total } \\
\text { delivery } \\
\mathbf{N}(\%)\end{array}$ & $\begin{array}{l}\text { Number of } \\
\text { vaginal delivery } \\
\mathbf{N}(\%)\end{array}$ & $\begin{array}{l}\text { Number of } \\
\text { caesarean delivery } \\
\mathbf{N}(\%)\end{array}$ \\
\hline $1969(100)$ & $1439(73.08)$ & $530(26.92)$ \\
\hline
\end{tabular}

Table 2: Parity vs. mode of delivery.

\begin{tabular}{|lll|ll} 
Total & $\begin{array}{l}\text { Total } \\
\text { vaginal } \\
\text { delivery } \\
\text { in primi } \\
\text { mother }\end{array}$ & $\begin{array}{l}\text { Total } \\
\text { caesarean } \\
\text { delivery in } \\
\text { primi } \\
\text { mother }\end{array}$ & $\begin{array}{l}\text { Total } \\
\text { vaginal } \\
\text { delivery } \\
\text { in multi } \\
\text { mother }\end{array}$ & $\begin{array}{l}\text { Total } \\
\text { caesarean } \\
\text { delivery } \\
\text { in multi } \\
\text { mother }\end{array}$ \\
\hline 1969 & 751 & 301 & 688 & 229 \\
\hline
\end{tabular}

Total $62 \%$ of mothers were willing for PPIUCD but finally around half of total delivery $(49.97 \%)$ received PPIUCD (Table 3-4).

Table 3: Percentage of mode of delivery vs. parity.

\begin{tabular}{|lll|}
$\begin{array}{l}\text { Mode of } \\
\text { delivery }\end{array}$ & $\begin{array}{l}\text { Primi mother } \\
(\%)\end{array}$ & $\begin{array}{l}\text { Multi mother } \\
(\%)\end{array}$ \\
\hline Vaginal & 59 & 75.02 \\
\hline Caesarean & 41 & 24.98 \\
\hline
\end{tabular}

Table 4: Percentage of PPIUCD willing mother.

\begin{tabular}{|ll|}
\hline Total delivery & Total PPIUCD willing \\
$\mathbf{N}(\%)$ & mother N $(\%)$ \\
\hline $\mathbf{1 9 6 9}(\mathbf{1 0 0})$ & $1221(62)$ \\
\hline
\end{tabular}

PPIUCD acceptance is higher $(68 \%)$ in vaginal birth group (group A) than caesarean birth group (group B) (Table 5). Acceptance of PPIUCD Is more in multiparous mother $(54.44 \%)$ (Table 6). 
PPIUCD acceptance is higher in vaginal birth group (Group A) both in primi and multi mother (Table 7-8), and least $(13.61 \%)$ in caesarean birth group of multiparous mother. The proportion of women have PPIUCD insertion with primiparous, multiparous are $45.56 \%, 54.44 \%$ respectively.

It is found that PPIUCD insertion is more in vaginal delivery. $68 \%$ of total vaginal birth $40.87 \%$ and $27.13 \%$ are multiparous and primi women respectively. Non acceptance of PPIUCD is little higher in primi mother (Table 9). Total acceptance and non- acceptance ratio almost same.

Table 5: Acceptance of PPIUCD in vaginal and caesarean delivery.

\begin{tabular}{|lll|}
\hline $\begin{array}{l}\text { Mode of } \\
\text { delivery }\end{array}$ & $\begin{array}{l}\text { Total PPIUCD } \\
\text { acceptance }\end{array}$ & $\begin{array}{l}\text { Percentage of } \\
\text { PPIUCD } \\
\text { acceptance }\end{array}$ \\
\hline $\begin{array}{l}\text { Vaginal } \\
\text { (group A) }\end{array}$ & 669 & 68 \\
\hline $\begin{array}{l}\text { Caesarean } \\
\text { (group B) }\end{array}$ & 315 & 32 \\
\hline
\end{tabular}

Table 6: Acceptance of PPIUCD in PRIMI and multi mother.

\begin{tabular}{|lll|}
$\begin{array}{l}\text { Parity of } \\
\text { mother accept }\end{array}$ & $\begin{array}{l}\text { Number of } \\
\text { PPIUCD } \\
\text { PPIUCD }\end{array}$ & $\begin{array}{l}\text { Percentage of } \\
\text { PPIUCD } \\
\text { acceptance }\end{array}$ \\
\hline Primi mother & 448 & 45.56 \\
\hline Multi mother & 536 & 54.44 \\
\hline
\end{tabular}

Table 7: Mode of delivery vs. PPIUCD acceptance in primiparous women $(n=984)$.

\begin{tabular}{|l|l|l|}
$\begin{array}{l}\text { Mode of } \\
\text { delivery in } \\
\text { primi mother }\end{array}$ & $\begin{array}{l}\text { Total of } \\
\text { PPIUCD } \\
\text { acceptance }\end{array}$ & $\begin{array}{l}\text { Percentage of } \\
\text { PPIUCD } \\
\text { acceptance }\end{array}$ \\
\hline Vaginal & 267 & 27.13 \\
\hline Caesarean & 181 & 18.39 \\
\hline
\end{tabular}

Table 8: Mode of delivery vs. PPIUCD acceptance in multiparous women $(n=984)$.

\begin{tabular}{|l|l|l|}
$\begin{array}{l}\text { Mode of } \\
\text { delivery in } \\
\text { primi mother }\end{array}$ & $\begin{array}{l}\text { Total of } \\
\text { PPIUCD } \\
\text { acceptance }\end{array}$ & $\begin{array}{l}\text { Percentage of } \\
\text { PPIUCD } \\
\text { acceptance }\end{array}$ \\
\hline Vaginal & 402 & 40.87 \\
\hline Caesarean & 134 & 13.61 \\
\hline
\end{tabular}

Table 9: Acceptance vs. non acceptance of PPIUCD.

\begin{tabular}{|lll|}
\hline PPIUCD & Primi mother & Multi mother \\
\hline Accepted -984 & 448 & 536 \\
\hline Not accepted -985 & 604 & 381 \\
\hline Total -1969 & 1052 & 971 \\
\hline
\end{tabular}

\section{DISCUSSION}

The IUCD is cost effective, easily accessible, highly effective, long acting, reversible, safe family planning method in post-partum period which is highly vulnerable period as there are limited contraceptive options available in the breast-feeding women. Postpartum period is potentially an ideal time to start contraception as women are more strongly motivated at this time, which also has the advantage of being convenient for both women and health-care providers. ${ }^{15}$ Early and repeated counselling of contraception during each antenatal visit was started from our PP Unit by all category of service care provider. So, around $95 \%$ of total no of delivery i.e. 1870 no. of mother were aware about PPIUCD at the time of admission at labour room in our hospital. Among them 62\% i.e. 1221 no. of mother were willing for PPIUCD voluntarily before client selection. After fulfilled all criteria 984 mother i.e. $49.97 \%$ of total delivery accepted and received PPIUCD. In our study PPIUCD acceptance is higher (68\%) in vaginal birth group (Group A) than caesarean birth group (Group B). Though The study conducted by Sangeetha et al it was found $43.9 \%$ of PPIUCD accepted who were underwent caesarean section and only $6.3 \%$ in vaginal delivery. ${ }^{16}$ Another study by Ramya et al found that PPIUCD acceptance was $34.1 \%$ and $29.7 \%$ in caesarean and vaginal delivery respectively. ${ }^{17}$ In our study total no of vaginal birth was more in multiparous women than primi. So acceptance of PPIUCD was more in multiparous vaginal birth i.e. $40.87 \%$. According to Katheit et al acceptance of PPIUCD was higher in multipara women. ${ }^{18}$ Main causes of low acceptance of PPIUCD in case of caesarean birth were fear of complication with surgical intervention, denial by husband and relatives, selection of other methods (for primi choose OCP, barrier method and for multi mother liked for permanent sterilisation). Our hospital is a 2nd tier hospital situated in urban area. Many mothers was referred from periphery centre who need emergency caesarean section. Many of them were not suitable candidate for IUCD. This was also one of important cause of low acceptance of PPIUCD in case of caesarean birth.

\section{CONCLUSION}

In current study the postpartum contraceptive intrauterine device acceptance among the vaginal birth group was higher than caesarean birth group. Most important cause for this acceptance was team work of health care provider of PP unit and indoor unit. Low acceptance in group B we can improve by giving more effort to get aware and educate the public. Peripheral health care provider should also counsel the women specially who had a previous history of caesarean section and try to remove their psychological fear. We can improve our awareness program through different media. Continuing the incentives to both client and service provider which will increase not only the acceptance but also maintain the rate of PPIUCD program. 
Funding: No funding sources

Conflict of interest: None declared

Ethical approval: The study was approved by the Institutional Ethics Committee

\section{REFERENCES}

1. National health mission, family planning. 2014-15. Available at: http://www.Family Planning:: National Health Mission (nhm.gov.in). Accessed on 20 October 2021.

2. National family health survey (NFHS-2). Available at: http://www.National Family Health Survey (rchiips.org). Accessed on 20 October 2021.

3. India National Family Health Survey. Available at: www.iipsindia.ac.in. Accessed on 20 October 2021.

4. Facility Survey (DLHS-4) 20012-13. National Data Sharing and Accessibility Policy (NDSAP). International Institute for Population Sciences. Available at: http://www.tipsindia.org. Accessed on 20 October 2021.

5. IUCD Reference manual for medical officers. Available at: http://www.3 IUCD Reference ManualDoctors.pdf (nhmnagaland.in). Accessed on 20 October 2021.

6. Post partum family planning: rationale for post partum family planning; healthy spacing for pregnancy. Available at: http://www.9789241506496_eng.pdf (who.int). Accessed on 20 October 2021.

7. Post-Partum IUD Reference Manual. Available at: http://www.bing.com/search?q=Post-Partum+IUD+ Reference+Manual\&qs=n\&form $=\mathrm{QBRE} \& \mathrm{sp}=-$ $1 \& p q=$ post-partum+iud+reference+manual $\& s c=132 \& s k=\& c v i d=24 C 2 B 9301 \mathrm{E} 814 \mathrm{C} 0 \mathrm{ABC} 02 \mathrm{D} 9$ B17AAD0478. Accessed on 20 October 2021.

8. Park K. Preventive and social medicine. 26th ed. USA: Ardent; 2019:505.

9. Salem RM. New attention to the IUD: expanding women's contraceptive options to meet their needs. Popul Rep B. 2006;(7):1-26.

10. Sivin I, Stern J, Diaz S, Pavéz M, Alvarez F, Brache $\mathrm{V}$, et al. Rates and outcomes of planned pregnancy after use of Norplant capsules, Norplant II rods, or levonorgestrel-releasing or copper $\mathrm{TCu} 380 \mathrm{Ag}$ intrauterine contraceptive devices. Am J Obstet Gynecol. 1992;166(4):1208-13.

11. Skjeldestad A. The intrauterine devices subsequent fertility. Curr Opin Obstet Gynecol. 2008;20(3):27580.

12. Schwarz D, Bimla E. Intrauterine contraceptives (IUCs)". In: Hatcher A, Robert A, Trussell J, Nelson AWK, Deborah PMS. Contraceptive technology. 20th ed. New York: Ardent 2011; 147-91.

13. Eroglu K, Akkuzu G, Vural G, Dilbaz B, Akin A, Takin L, et al. Comparison of efficacy and complications of IUD insertion in immediate postplacental/early postpartum period with interval period: 1 year follow-up. Contraception. 2006;74(5): 376-81.

14. Goldstuck ND, Steyn PS. Intrauterine contraception after cesarean section and during lactation: a systematic review. Int J Womens Health. 2013;5:8118.

15. Xu JX, Reusche C, Burdan A. Immediate postplacental insertion of intrauterine device: $A$ review of Chinese and world experiences. Adv Contracept. 1994;10:71-82.

16. Jairaj S, Dayyala S. A cross sectional study on acceptability and safety of IUCD among postpartum mothers at tertiary care hospital, Telangana. JCDR. 2016;10(1):LC01.

17. Ramya KS. A comparative study of PPIUCD acceptance between primiparaous and multiparaous women in a tertiary care hospital in Tamil Nadu. IJRCOG. 2017;6(8):3569-72.

18. Katheit G, Agarwalet J. Evaluation of post-placental intrauterine device (PPIUCD) in terms of awareness, acceptance, and expulsion in a tertiary care centre. Int J Reprod Contracept Obstet Gynecol. 2013;2(4):53943.

Cite this article as: Biswas C, Biswas B. A comparative study of postpartum intrauterine contraceptive device acceptance between vaginal delivery and caesarean delivery of women in a 2 nd tire Government hospital in West Bengal, India Int $\mathbf{J}$ Reprod Contracept Obstet Gynecol2022;11:882-6. 